\title{
Los muertos escribieron su relato: postmemoria y metaficción en la Europa del siglo XXI
}

\author{
The dead wrote their memory: \\ Postmemory and metafiction in 21 st century Europe
}

Juan Manuel Martín Martín

Universidad de Salamanca.jm.mm@usal.es

Recibido: 23.06.2019. Aceptado: 18.07.2019

Resumen: Tanto en España como en Alemania el discurso público oficial se ha debatido entre el recuerdo de las víctimas y un necesario olvido con la vista puesta en el futuro. La literatura ha asumido en general la responsabilidad de mantener viva la memoria de los muertos que la traumática historia del siglo XX dejó en Europa. Las obras de Alberto Méndez y Michel Bergmann reflejan ese pasado en el marco de una "postmemoria" propia de los descendientes de la generación de los testigos. La fuerza del testimonio de estos se incorpora a los textos Manuscrito encontrado en el olvido (2004) y Weinhebers Koffer (2015) a través de la metaficción, convertida en un recurso que permite dotar de voz a los muertos.

Palabras clave: metaficción; postmemoria; memoria generacional; Guerra Civil española; Holocausto.

\begin{abstract}
In Spain, as well as Germany, the official public discourse has struggled between remembering the victims and a necessary oblivion in order to focus on the future. In general, literature has taken on the responsibility of keeping alive the memory of the dead left by the traumatic history of Europe's twentieth century. The works of Alberto Méndez and Michel Bergman reflect such time, framed by the "postmemory" typical of the descendants of the witnessing generation. The powerful testimonies of these witnesses are incorporated into the works Manuscrito encontrado en el olvido (2004) and Weinhebers Koffer (2015) through metafiction turned into a resource that allows the dead to have their own voice.
\end{abstract}

Keywords: metafiction; postmemory; generational memory; Spanish Civil War; Holocaust.

》) Martín Martín, Juan Manuel. 2019. "Los muertos escribieron su relato: postmemoria y metaficción en la Europa del siglo XXI". Quaderns de Filologia: Estudis Literaris XXIV: 197-216. doi: 10.7203/qdfed.24.16340 



\section{Políticas sobre el pasado y memoria generacional}

Alberto Méndez (1941-2004) y Michel Bergmann (1945) son dos escritores cuyos universos literarios se construyen sobre los acontecimientos traumáticos del siglo XX europeo. Las guerras tras las que nacen tienen un importante significado para la conformación de su memoria literaria del pasado ${ }^{1}$. No forman parte, por tanto, de la generación que presencia los hechos de forma directa, sino de quienes conviven con esta y crecen rodeados de los testimonios o silencios de sus progenitores. La adscripción generacional será determinante para comprender e interpretar el modo en que ambos se posicionan frente al pasado. Tanto en Manuscrito encontrado en el olvido ${ }^{2}$ como en Weinhebers Koffer ${ }^{3}$ se ponen de manifiesto semejanzas que dejan traslucir un substrato que sobrepasa las particularidades de cada autor y su entorno: los muertos que claman contra la marginación de su memoria en todos los rincones del continente.

\subsection{Política del olvido frente a la recuperación de las víctimas}

En medio de las ruinas, con las heridas físicas y mentales muy abiertas, el canciller alemán Konrad Adenauer manifiesta en su primera Declaración gubernamental que el Gobierno está decidido a dejar atrás el pasado, si bien trata de matizar que se sacarán de él las enseñanzas necesarias frente a las fuerzas que puedan poner en peligro la República (radicales de derechas e izquierdas) 4 . La necesidad de estable-

\footnotetext{
${ }^{1}$ Bergmann llega al mundo en enero de 1945, en un campo de refugiados judíos en Suiza, es decir, pocos meses antes de que finalice la II Guerra Mundial. En el caso de Méndez, nace cuando apenas han transcurrido dos años desde la derrota de los republicanos españoles en la Guerra Civil.

${ }^{2}$ El título completo del relato es Segunda derrota: 1940 o Manuscrito encontrado en el olvido. Es la segunda de las cuatro narraciones que conforman el volumen Los girasoles ciegos (2004), con el que el autor obtuvo con carácter póstumo tanto el Premio de la Crítica como el Premio Nacional de Narrativa. Las referencias a este texto aparecerán aquí como MO.

${ }^{3}$ La obra Weinhebers Koffer (La maleta de Weinheber) (2015) no ha sido editada en España, de modo que las citas que aparecen aquí en castellano son traducciones propias. Las referencias a esta breve novela se presentarán como MW.

${ }^{4}$ Esta primera Regierungserklärung tiene lugar el 20 de septiembre de 1949 y marca las líneas del discurso oficial frente al pasado en la República Federal de Alemania. El
} 
cer una cesura frente al pasado que permita concentrarse en resolver las dificultades presentes más apremiantes caracteriza también otra declaración política, en este caso del presidente del Gobierno español Felipe González, denominada Declaración institucional del gobierno con ocasión del cincuenta aniversario del comienzo de la guerra civil (18-VII-1986). A pesar de la distancia temporal respecto al hecho que se conmemora, no debemos perder de vista que pocos años antes, en 1981, había tenido lugar un intento de golpe de Estado. González explicita la necesidad de dejar atrás el conflicto bélico de los años treinta en España:

La guerra civil española es definitivamente historia, parte de la memoria de los españoles y de su experiencia colectiva. Pero no tiene ya -ni debe tenerla- presencia viva en la realidad de un país cuya conciencia moral última se base en los principios de la libertad y de la tolerancia (...) El gobierno expresa su convicción de que España ha demostrado reiteradamente su voluntad de olvidar las heridas abiertas en el cuerpo nacional por la guerra civil, su voluntad de vivir en un orden político basado en la tolerancia y la convivencia, en el que la memoria de la guerra sea, en todo caso, un estímulo para la paz y el entendimiento entre todos los españoles ${ }^{5}$ (González, 1986).

Aparte del interés por cerrar el capítulo de un pasado conflictivo, en el intrincado camino seguido por el discurso político a menudo han tenido un espacio relevante las víctimas, entendidas estas en un sentido amplio que abarca tanto los muertos como los supervivientes del trauma. Mucho tiempo antes de que se hablara en España de memoria histórica,

texto completo de esta declaración es accesible en: https://www.konrad-adenauer.de/ dokumente/erklaerungen/1949-09-20-regierungserklaerung.

${ }^{5}$ Más allá de la confusa utilización de los términos historia y memoria que aparece en la Declaración, el embrollo conceptual sí parece dejar claro que aquella guerra forma parte del pasado y no ha de tener un protagonismo específico en la actualidad del momento. ${ }^{6}$ La memoria histórica supone una "conceptualización crítica de acontecimientos de signo histórico compartidos colectivamente y vivos en el horizonte referencial de un determinado grupo" (Colmeiro, 2005: 18). En el ámbito de Alemania, el concepto de Vergangenheitsbewältigung supondría una equivalencia aproximada con este término, pues representa el proceso de confrontación crítica de la sociedad alemana con el pasado 1933-1945 que comienza nada más finalizar ese periodo y que se prolonga hasta el día de hoy. Está determinado por diferentes etapas en las que las sucesivas generaciones han ido desempeñando roles cambiantes. Véase a este respecto Frei (2009: 38-55). 
el dictador Franco "fue el primero en pedir censos de desaparecidos, el primero en encargar a un grupo de expertos un protocolo de exhumaciones y, hasta ahora, el único que preservó por ley las fosas comunes para que no se construyera sobre ellas" (Pérez/Manzano, 2010: 16). Estas intenciones adquirieron carta de naturaleza con la publicación en el Boletín Oficial del Estado de diversas medidas legislativas desde el mismo inicio de la contienda ${ }^{7}$. Obviamente, la preocupación de Franco se refería solo a sus víctimas, es decir, las que habían combatido en el denominado bando nacional o se consideraban afín a este.

La recuperación de las víctimas en el discurso oficial parece inevitable, y de ello queda constancia tanto en España como en Alemania. A pesar de que los contextos son muy diferentes, sí se pone de manifiesto una necesidad de retomar un hilo de recuerdo que las circunstancias habían debilitado. El 8 de mayo de 1985, cuarenta años después de la rendición de Alemania tras la II Guerra Mundial, el entonces presidente de la RFA Richard von Weizsäcker pronuncia un discurso que representa un punto de inflexión en la forma en que los gobernantes alemanes se acercan al pasado. La conocida habitualmente como Weizsäckers Rede celebra la efeméride como la conmemoración de una liberación, no tanto como la derrota de la que se llevaba hablando durante décadas (Weizsäcker, 2019). En cualquier caso, lo relevante aquí es el espacio que su discurso concede a las víctimas del nacionalsocialismo y la guerra, pues da cabida a un amplio número de colectivos que complementan a los que habitualmente se habían considerado ${ }^{8}$. La mención expresa del sufrimiento alemán junto al sufrimiento causado por los alemanes adelanta un planteamiento que pocos años después, tras el fin de la Guerra Fría, quedará consolidado con la aparición de un renovado Opferdiskurs (discurso de las víctimas) que pretende recuperar

Es bastante claro, además, que Alemania ha sido un modelo para España en lo referente a las políticas de memoria, tanto respecto a las medidas gubernamentales como en los debates públicos (Silva, 2009: 179).

7 Véase a este respecto el artículo "Franco inventó la memoria histórica" (Junquera, 2009).

${ }^{8}$ Además de los judíos y las víctimas polacas y soviéticas, que son los mencionados en primer lugar, Weizsäcker se refiere a los soldados alemanes, gitanos, homosexuales, enfermos mentales, rehenes ejecutados, opositores al nazismo dentro y fuera de Alemania, los descendientes de los muertos en la guerra o los mutilados. Finalmente, se concede espacio a las víctimas alemanas en un sentido amplio: bombardeos aéreos, refugiados y deportados, violaciones, trabajos forzosos, torturas, hambre. 
el dolor que los alemanes habían tenido que silenciar obligados por el peso de su propia culpa. Como señala Andrew H. Beattie: "While von Weizsäcker sought to recall all who had suffered, he nevertheless gave primacy to the Holocaust and its Jewish victims. It was the pinnacle of an inclusive, differentiating approach to the past" (Beattie, 2006: 154). El discurso va dirigido tanto a la sociedad alemana como a un auditorio internacional, y hace una estimable contribución al apuntalamiento de la memoria de los muertos, de todos ellos.

El resultado de la guerra civil española y la posterior dictadura determinaron unos tiempos muy diferentes a los de la Europa democrática respecto a las políticas de memoria. Mientras que Franco había tratado de redimir a sus difuntos cuando las armas aún seguían en alto, Felipe González se revestiría de prudencia medio siglo después haciendo un llamamiento más o menos explícito al olvido. Se trataba de conjurar los peligros que acechaban a la joven democracia. Ya en el siglo XXI, consolidado el auge del debate sobre la memoria que se desarrolla con una dimensión globalizada, José Luis Rodríguez Zapatero, segundo presidente socialista tras la recuperación de la democracia en España, presenta su polémica Ley de la memoria histórica ${ }^{9}$, en un intento de hacer justicia fundamentalmente con las víctimas del bando perdedor y consolar a sus frustrados y decepcionados descendientes. De los muchos aspectos de aquella medida legislativa, la que suscitó más debates y tuvo una mayor repercusión mediática fue la relativa a la búsqueda e identificación de los miles de cadáveres desperdigados por toda la geografía del país ${ }^{10}$. Con la mención de los muertos se despertaron también muchos fantasmas de enemistad y revancha, miedos que aparentemente habían sido conjurados tras la Transición. Se puso de manifiesto que los muertos no solo estaban en las cunetas, sino que habían sobrevivido con

\footnotetext{
${ }^{9}$ El nombre exacto de la ley es Ley 52/2007, de 26 de diciembre, por la que se reconocen y amplían derechos y se establecen medidas a favor de quienes padecieron la persecución o violencia durante la Guerra Civil y la dictadura (BOE, N. ${ }^{\circ} 310$ de 27/12/2007). ${ }^{10}$ Para comprender el contexto en el que aparece la ley, así como alguno de sus aspectos más controvertidos, conviene hacer referencia al surgimiento en el año 2000 de la Asociación para la Recuperación de la Memoria Histórica (ARMH). Esta se funda a partir del descubrimiento de unas fosas anónimas de republicanos fusilados en la Guerra Civil en El Bierzo. Estos hechos y los de las búsquedas e identificaciones que los sucedieron daban buena cuenta de que se había quebrado al menos parcialmente el consenso de silencio y olvido que había posibilitado la ya superada Transición.
} 
fuerza inusitada en la memoria más íntima de los derrotados. Y estos no pertenecían ya a la generación que vivió los acontecimientos, sino que se trataba de sus descendientes, portadores ahora de la memoria de aquellos.

Este intento de rehabilitación del recuerdo de los perdedores se produce en un contexto de polarización ideológica del país que parece reproducir una escisión atávica. No solo los vencedores habían construido una memoria más o menos institucionalizada, también los diferentes grupos que pierden la guerra elaboran un discurso memorialístico para sus adeptos (Pérez/Manzano, 2010: 32-33). Más allá de los intentos de unos y otros, el vencedor tiene de su lado la autoridad y es capaz de determinar la historia, mientras que "[e]l vencido deja un vacío, una ausencia, que será moralmente significativa, pero que políticamente dependerá de otros, de quienes la recuerden y valoren" (Mate, 2015: 31). Así que el nuevo siglo y las generaciones de la postmemoria habrán de poner orden en un panorama complejo que pone en tela de juicio muchos de los presupuestos asumidos tradicionalmente.

\subsection{Generaciones y herencias: postmemoria familiar y postmemoria fliativa}

Nos vamos a servir aquí del concepto de postmemoria que elabora Marianne Hirsch a principios de los años noventa y que se refiere específicamente al recuerdo del Holocausto ${ }^{11}$. Partiendo de los insoslayables paralelismos entre las memorias traumáticas del devenir histórico durante los años treinta y cuarenta en Europa, la postmemoria que la autora describe en relación con el genocidio de los judíos europeos sería

\footnotetext{
${ }^{11}$ La oportunidad de aplicar este concepto a realidades diferentes al Holocausto está avalada tanto por los paralelismos que estableceremos entre dos experiencias traumáticas de carácter colectivo, como por el desarrollo actual de una memoria colectiva transnacional "que puede ser entendida, de un modo general, como epifenómeno de los cambios políticos, sociales, epistemológicos, culturales y mediáticos subsumidos bajo el término de globalización" (Jünke, 2015: 152-3). No estamos tratando de sugerir que haya paralelismos entre el Holocausto y la represión de los republicanos españoles, sino en el modo en que se han transmitido sus recuerdos y se han construido las "postmemorias" de sus descendientes. Asimismo, esta idea se puede apoyar también en el concepto de "memoria multidireccional" planteado por Michael Rothberg (2009), según el cual una memoria traumática en un contexto puede inspirar y fomentar la memoria de otros sucesos en otros contextos.
} 
extrapolable a otros marcos. Así explica Hirsch en qué consiste el término:

"Postmemory" describes the relationship that the "generation after" bears to the personal, collective, and cultural trauma of those who came before - to experiences they "remember" only by means of the stories, images, and behaviors among which they grow up. But these experiences were transmitted to them so deeply and affectively as to seem to constitute memories in their own right. Postmemory's connection to the past is thus actually mediated not by recall but by imaginative investment, projection, and creation (2012: 5).

Ni Alberto Méndez ni Michel Bergmann pertenecen a la Zeitzeugengeneration (la generación de los testigos), sino que disponen de un recuerdo derivado de la memoria compartida con sus predecesores. Ambos son ejemplo del boom memorialístico de las últimas décadas que desea colocar el pasado como una parte indispensable del presente (Assmann, 2010: 39). En el caso del autor alemán, su nexo con los hechos históricos en los que está anclada su obra resulta más evidente, ya que sus padres consiguen sobrevivir al Holocausto. Esta generación vive durante su infancia inmersa en una realidad duplicada: la del pasado de sus progenitores y la del presente propio (Steinecke, 2005: 8). Confrontada, por tanto, con el peso de los recuerdos familiares que pueblan un mundo en el que los hechos que produjeron el trauma ya han cesado. A menudo ese entorno está poblado de silencios, y estos también son determinantes para la construcción de la identidad de los descendientes. Como señala Julia Herzberger: "Las generaciones posteriores buscan un pasado que a menudo les es desconocido, pero que implica amplias consecuencias para la propia biografía y para el hallazgo de la identidad" (2009: 1). Esta es una constante de gran parte de las reflexiones en torno a la memoria de los últimos tiempos: la relevancia y significación de los hechos pasados en la conformación de las realidades presentes ${ }^{12}$.

En una entrevista explicaba Alberto Méndez que su familia había sido republicana y en la posguerra había decidido abandonar España, si bien en su caso debido a motivos económicos y no políticos (Rendueles,

\footnotetext{
${ }^{12}$ Andreas Huyssen incide en un cambio que se produce a partir de los años ochenta que implica que el centro de interés ya no se sitúa en lo que él denomina "present futures" sino en los "present pasts" (2003: 11).
} 
2004). De hecho, si consideramos que un poemario de su padre es premiado en 1945 por la Real Academia de la Lengua, podemos inferir que los Méndez no se encontraban entre los que fueron represaliados. A pesar de ello, su familia sí se relacionó estrechamente con estos en su exilio voluntario en Italia: "el núcleo de españoles de Roma eran casi todos viejos republicanos que habían hecho la Guerra. Esos sí que eran exiliados políticos. Y ellos nos hablaban de la República y de la Guerra" (Rendueles, 2004). La relación de Méndez con el trauma derivado del periodo 1933-1939 constituiría su postmemoria, alimentada en este caso por la interacción con el mundo de los testigos de los hechos. Las consecuencias de las experiencias vividas por el autor en su adolescencia y juventud entre los republicanos bien pudieron estar en su decisión de militar en el Partido Comunista, militancia que mantendría hasta el principio de los años ochenta.

Tanto Bergmann como Méndez han estado inmersos en un proceso en el que la memoria de las víctimas de acontecimientos históricos que arrasaron sus países ha resultado esencial para la construcción de la propia identidad. Sin embargo, su relación con los hechos que constituyen su memoria ha de ser interpretada sin perder de vista que en el caso del autor alemán el trauma forma parte inherente de la experiencia de su familia, mientras que, en el caso de Méndez, el recuerdo de este sufrimiento llega a través de la memoria comunicativa que nace del contacto con los exiliados que vivieron los momentos dolorosos. Es pertinente aquí la distinción que Hirsch establece entre la postmemoria familiar y la postmemoria filiativa ${ }^{13}$ :

[W] would have to account for the difference between an intergenerational vertical identification of child and parent occurring within the family, and the intragenerational horizontal identification that makes that child's position more broadly available to other contemporaries (2012: 35-36).

\footnotetext{
${ }^{13}$ La autora establece esta diferenciación para referirse a la obra de Art Spiegelman (autor de la novela gráfica Maus) y de W. G. Sebald (autor entre otras novelas de Austerlitz). Ambos, al igual que los dos autores a los que nos estamos refiriendo en este artículo, pertenecen a la generación posterior a los testigos de los hechos, pero mientras que el primero desciende de supervivientes del Holocausto, el segundo pertenece a una familia de alemanes no judíos que no fueron por tanto víctimas de la persecución. Tienen en común que en sus obras se lleva a cabo una búsqueda intensa del significado del trauma para los descendientes y su mundo.
} 
Para el universo experiencial de los dos autores son esenciales los traumas colectivos de sus respectivos países, no obstante, esta identificación (horizontal o vertical) los conecta con ellos a través de ejes diferentes. Para el análisis comparativo que pretendemos establecer, es más relevante el resultado artístico de la postmemoria de Méndez y Bergmann que la naturaleza familiar o filiativa de su contacto con el pasado. Ambos comparten su adscripción generacional, el no pertenecer a la que podríamos denominar "primera generación", la que estuvo implicada de manera directa en los acontecimientos, y esto tiene una implicación en la decisión de recurrir dentro de su ficción literaria al testimonio directo de personajes que sí pertenecieron a ella: el poeta del relato de Méndez y el novelista del texto de Bergmann. La naturaleza metaficcional de sus obras les permite introducir las palabras de la generación de los testigos, así como los esfuerzos de los descendientes que luchan por recuperar sus palabras. Estas se convierten así en una pieza más en la construcción de la postmemoria de estos personajes que, en ese aspecto particular, son un alter ego de los autores.

\section{Metaficción: el testimonio sin intermediarios}

A pesar de que aparentemente el discurso posmoderno no otorga importancia a la autenticidad y la factualidad (Assmann, 2011: 218), diversas obras metaficcionales incorporan textos que representan un escalón intermedio entre la pura ficción y la realidad. No se trata de engañar al lector, sino de ofrecer el testimonio directo de determinadas figuras integradas en la irrealidad narrativa. Es un intento de mostrarnos sin intermediarios aparentes las palabras de los muertos, rescatadas con posterioridad por personajes pertenecientes a la generación que sucede a aquellas víctimas. Así ocurre en las dos obras que vamos a utilizar como ejemplo.

Reyes Mate insiste en la importancia de la figura del testigo para conocer la realidad; en Memorias Auschwitz explica que a menudo hablar era su razón de vivir. Y si ellos necesitaban relatar su experiencia, los descendientes sienten la obligación de escuchar (2003: 170). Como se indicó más arriba, los autores vivieron parte de su vida rodeados de personas, fueran o no parte de su familia, que se enfrentaron en primera 
persona a hechos históricos traumáticos ${ }^{14}$. Más allá de que las experiencias del pasado sean compartidas y de la eventual solidaridad que se pueda establecer, hay un aspecto incontrovertible: solo una parte de la comunidad vivió los hechos que se incorporan a la memoria del conjunto. Esto los coloca en un lugar diferenciado: el suyo es el testimonio de los hechos. Los demás han de conformarse con un derivado, sea este denominado postmemoria o no. Las generaciones posteriores a la de los testigos han de asumir el papel de espectadores, por muy cercanos que se sientan al trauma colectivo y aunque este haya sido determinante en sus vidas.

Precisamente la literatura posibilita una ilusión de fusión entre estos diferentes niveles experienciales, pues a través de la ficción se pueden crear universos en los que se desvanezca la imposibilidad de vivir un tiempo que ya pasó. La construcción de un relato metaficcional apoyado en las palabras de víctimas que dejaron su testimonio antes de morir, permite a los autores traspasar la barrera y transformarse en testigos, ascender así al primer nivel de contacto con la experiencia de la que se quiere dar testimonio. En realidad, gracias a la creación artística asumen el rol propio de su generación y el de la que los precedió. Sus obras ofrecen, por un lado, el testimonio y, por otro, presentan a los receptores de este, que tienen cuando menos la obligación de preservar las palabras de los muertos que ya no están en disposición de hacerlo. Se trata de hacer justicia con la memoria de estos, ya que sobre el pasado no se puede intervenir. Señala Mate que "el testigo pide con su testimonio que se haga justicia, tomando al interlocutor como juez, es decir, como quien puede hacer justicia" (2003: 185).

Esa justicia, como veremos más adelante, deriva de la conjuración del olvido de los muertos y sus palabras. La obligación de recordarlos es un aspecto central en el discurso sobre el Holocausto; además, el hasidismo atribuye una función redentora al recuerdo (Schmitz, 2004: 309). Asimismo, en las dos obras a las que nos referimos aquí, adquiere relevancia identificar a los testigos que han dejado por escrito sus testimonios. Thomas W. Laqueur indica respecto a los nombres de los

\footnotetext{
${ }^{14}$ En el marco de esa interacción social se desarrolla la "memoria colectiva" de la que hablaba Maurice Halbwachs a principios del siglo XX en Les cadres sociaux de la mémoire (1925). Sus conceptos son recogidos por Aleida y Jan Assmann en las últimas décadas, quienes incorporan los términos de memoria comunicativa y memoria cultural.
} 
muertos: "[the names of the dead] evoke, commemorate, beckon, stand and speak for the dead, singly and collectively" $(2015: 367)^{15}$. En este sentido, el nombre de las dos figuras del relato de Méndez y de la novela de Bergmann se convierten en denominaciones transferibles a otros muchos que se vieron inmersos en su terrible destino.

En Manuscrito encontrado en el olvido se presentan las páginas de un diario encontradas en 1940 junto a los cadáveres de un hombre y un bebé. Estas son acompañadas de breves acotaciones de un narrador que se autodenomina editor; este informa al final del relato de que en 1954 sus investigaciones lo condujeron a una aldea en la que encontró pistas de una figura que podría corresponder al autor del diario. El caso de $L a$ maleta de Weinheber es más complejo, pues todo se desarrolla a partir del hallazgo fortuito de una maleta que lleva escritas las iniciales LW, que corresponden a Leonard Weinheber. Investigar su pasado se convertirá en el objetivo prioritario del narrador intradiegético; en este proceso llegará a sus manos una novela escrita por el tal Leonard en 1931.

Las palabras del poeta republicano español y del judío desesperado se convierten en un fundamento imprescindible de las obras en las que están incluidas. Recurrir a la metaficción permite establecer un nexo directo con la voz de los testigos, con el testimonio de la generación implicada en los hechos. En ambos casos perdura la voz de los muertos más allá del trágico desenlace de las vidas de los protagonistas, bien hasta 1954, bien hasta la actualidad del siglo XXI. Tanto Alberto Méndez como Michel Bergmann crean obras que hacen una llamada a la realidad presente desde la que aquellos desastres han de ser revisados. Linda Hutcheon incide en esta vinculación como algo propio de la posmodernidad: "Postmodern fiction suggests that to re-write or to re-present the past in fiction and in history is, in both cases, to open it up to the

\footnotetext{
${ }^{15}$ Tanto Michel Bergmann en su novela (MW: 15) como Laqueur en su extenso tratado sobre los muertos (2015: 433) hacen referencia a las Stolpersteine, una iniciativa artística que supone colocar pequeños adoquines metálicos para recordar a las víctimas del Holocausto junto al lugar donde vivían (o trabajaban). A través de ellos, se recuerda fundamentalmente su nombre y la fecha de su deportación y asesinato. De ese modo se establece un puente entre el pasado y el presente, entre la muerte y la vida de estas personas antes del desastre, así como entre la vida de los viandantes y la muerte de las víctimas: "They are not tombstones, both for the obvious reason that there is no body but also because Stolpersteine do not claim to be a substitute for an absent body or grave. They announce where somebody lived, not died. That said, passersby are often reluctant to step on them; the dead seem present" (Laqueur, 2015: 433).
} 
present, to prevent it from being conclusive and teleological" (1988: 110). Precisamente, la necesidad que parecen mostrar estos autores de dar voz a la generación que los precedió incide en el protagonismo que adquieren los hechos que ellos narran como parte de un devenir histórico que preserva la memoria de estos personajes-testigos: Eulalio Ceballos Suárez y Leonard Weinheber.

Los dos testigos recuperan sus nombres, los dos personajes deciden en alguna medida acabar con sus vidas, no sin antes asentar por escrito qué les ha conducido hasta el suicidio. Las víctimas perduran en sus palabras, los muertos no lo son tanto mientras alguien se coloque en el puesto de interlocutor.

\section{La huella de los muertos: testimonios y nombres}

Los dos personajes centrales de las obras analizadas deciden de una manera más o menos voluntaria acabar con su vida ${ }^{16}$. Sin embargo, dejan tras de sí un testimonio que es más importante que su pervivencia biológica. Dejan sus palabras, las que van a recuperar los que solo pueden llegar a ellos a través de sus escritos. En ese sentido, quizá la víctima haya conseguido triunfar, en tanto en cuanto es la portadora de la verdad ${ }^{17}$ :

Solo nos podemos fiar de las víctimas, de sus testimonios, de su experiencia. Dicen algo fundamental que todos sabemos pero que nadie se ha tomado en serio: que la historia se ha construido sobre víctimas y que si queremos acabar con esa lógica histórica hay que convencerse de que el sufrimiento debe ser la condición de toda verdad (Mate, 2015: $35)$.

\footnotetext{
${ }^{16}$ En el caso de Manuscrito encontrado en el olvido la idea del suicidio es más discutible que en la otra obra. Aquí el joven poeta decide permanecer en la cabaña, "dejarnos atrapar por los fascistas sería lo mismo que regalarles otra victoria (MO: 42)". No hace ningún intento por salvarse a sí mismo ni al bebé. Establecemos un paralelismo entre el explícito suicido de Leonard Weinheber en el barco que lo lleva a Israel y el "abandono" de la lucha por vivir en el caso de Eulalio Ceballos.

${ }^{17}$ Respecto a la relación entre recuerdo y verdad, señala Sara Santamaría: "En un contexto de revalorización del testimonio, el recuerdo y la experiencia de los testigos ocupan un lugar preeminente como forma de establecer la verdad de lo ocurrido frente a otros discursos, como la historiografía o los derivados del uso político del pasado. La fiabilidad otorgada a la memoria vincula estrechamente el recuerdo con aquello que es considerado verdadero" (2012: 57).
} 
Como veremos a continuación, las palabras, los nombres de los testigos-víctimas, su discurso, se convierten en su única posibilidad de supervivencia ${ }^{18}$. De ahí que la literatura provea un espacio metaficcional que las albergue.

\subsection{La maleta de Weinheber: en este mundo solo queda morir}

Las pesquisas del narrador de la obra, Elias Ehrenwert, para dilucidar la misteriosa desaparición del dueño de la maleta se convertirán en el eje sobre el que se mueve momentáneamente toda su vida ${ }^{19}$. La investigación establece un puente entre la Alemania de los años treinta y la actual, en la que Elias, de padre judío, sigue percibiendo cierta incomprensión y desconocimiento respecto a la minoría a la que pertenece su familia paterna. La obra escrita por Leonard Weinheber, las cartas que recibió de su amada Lenka Rosen, incluso los nombres de los padres de Leonard grabados sobre dos Stolpersteine junto al domicilio familiar en Berlín ${ }^{20}$, son los lugares donde el pasado deja constancia de que hubo un tiempo antes de la catástrofe. Son los nombres de los muertos, las palabras que escribieron y que los testigos ponen a disposición de las generaciones posteriores, implicadas así en el proceso memorialístico que los une a las víctimas. Esto surge de una necesidad, ya que "el testigo se disuelve si no tienen herederos, por eso busca al lector, al oyente o al espectador, para convertirlos en testigo ${ }^{21 "}$ (Mate, 2003: 182).

\footnotetext{
${ }^{18}$ La mera evocación del pasado no permite llegar al fondo del sufrimiento de las víctimas (Mate, 1991: 212-213), de ahí la relevancia de recurrir a su testimonio directo, que se logra a través de la metaficción.

${ }^{19}$ La investigación de la desaparición de Leonard Weinheber solo puede tener lugar una vez que se ha averiguado el nombre de este. Es decir, conocer la identidad del personaje es el punto de partida para interesarse por las vicisitudes a las que este se ha enfrentado. ${ }^{20}$ Véase nota 15.

${ }^{21}$ Este interlocutor del relato del testigo primigenio también es denominado espectador por Reyes Mate (2003: 204). En ambas obras encontramos un espectador que tiene entre sus manos el testimonio del testigo. En el relato de Méndez es una instancia anónima que asume el papel de mero presentador del manuscrito, sin embargo, Bergmann dota al narrador de mayor protagonismo, ya que no solo investiga activamente, sino que además se implica emocionalmente en los hechos pasados. Aunque existe una solidaridad moral en el tándem testigo-espectador de ambas obras, esta es más evidente en La maleta de Weinheber, en gran parte debido al elemento aglutinador que representa el judaísmo.
} 
La novela de Weinheber tiene el título de La ciudad sangrante (Die blutende Stadt). El argumento se desarrolla en Berlín, y la acción la desencadenan los disturbios antisemitas que se produjeron en la capital durante el mes de noviembre de 1923. Este texto metaficcional, del que solo se ofrecen algunos pasajes, es introducido por una breve nota de su autor:

Advertencia del autor:

"La simiente antisemita ha brotado", escribía el Vorwärts en su editorial del 8 de noviembre de 1923. "Berlín ha tenido su pogromo. Berlín ha sido deshonrado. Una vergüenza para un pueblo que se cuenta entre los civilizados".

El siguiente manuscrito trata los hechos que se desarrollaron el 5 de noviembre de 1923 en el barrio judío de Berlín. Los personajes han sido inventados; cualquier similitud con personas vivas o muertas no es intencionada y sería una simple coincidencia (WK: 45).

Esta "novela dentro de la novela" es un instrumento de un contemporáneo de los hechos para dejar constancia a través de la literatura de desgraciados acontecimientos históricos que adelantaban el genocidio que estaba por llegar. Al igual que el autor del diario que se incluye en el relato de Méndez, el autor de esta novela muere como consecuencia de las experiencias traumáticas. La hipótesis de que él mismo decide poner fin a su vida queda confirmada en las últimas líneas de la novela de Bergmann, de nuevo mediante un texto metaficcional. Se trata de un breve poema que Leonard Weinheber le dedica a Cary Mayers, una pasajera que ha conocido durante la travesía. Sus versos explican de forma simbólica que ha decidido terminar con su vida: "Cuando llega la mañana, / será tu mañana. / Y el sol brillará en la nueva vida. / El mar te muestra el camino hacia la luz. / A mí me conduce a casa" (MW: 142). El único hogar que el mundo de 1939 parece ofrecerle a Leonard es la muerte.

El misterio de la desaparición de Leonard solo se resuelve en las últimas páginas, cuando el narrador averigua que antes de llegar a Israel, al escritor le comunican que su amada Lenka Rosen, con la que espera reunirse allí, ha muerto durante un ataque árabe en abril de $1939^{22}$. En

\footnotetext{
${ }^{22}$ En el kibutz donde ocurrieron los hechos se conserva una placa conmemorativa que contiene el nombre de Lenka y otras víctimas (MW: 101). De nuevo el nombre aparece como el refugio de la memoria de los muertos.
} 
este punto se dan la mano ficción y metaficción, ya que el protagonista de La ciudad sangrante, la novela escrita por Leonard, se quita la vida como consecuencia de la frustración y el desengaño en el Berlín de 1923. Lo mismo hará el autor, que nunca llega a su destino en Jaffa ni desciende del barco que lo trasladaba desde Marsella hasta su frustrado encuentro con la mujer que ama.

Al final del libro se plantea la necesidad de publicar la novela escrita por Leonard en la Alemania del siglo XXI: la metaficción convertida así en ficción, estableciendo el diálogo último con los descendientes de los acontecimientos en los que se basa el texto.

\subsection{Manuscrito encontrado en el olvido: la memoria de la derrota}

A diferencia de lo que ocurre en La maleta de Weinheber, aquí la instancia que hace de intermediaria es anónima y no tiene casi ningún tipo de implicación emocional explícita en la presentación del diario recuperado. Una excepción representarían las últimas palabras del relato: "Si fue él el autor de este cuaderno, lo escribió cuando tenía dieciocho años y creo que ésa no es edad para tanto sufrimiento ${ }^{23 "}$ "(MO: 57). Esta es la única consideración que el narrador-editor hace, ya que este "actúa como una entidad testimonial que valida y confirma la autenticidad del manuscrito encontrado" (Cruz Suárez, 2013: 106). Asimismo, el relato comienza con informaciones relativas al entorno en que aparece el texto que provienen de un documento oficial: "reza el atestado" (MO: 39). Así pues, desde el principio queda clara la intención documental, recurso habitual que establece una conexión más estrecha con una factualidad que está situada más allá de la ficción. El diario ha sido conservado, igual que el atestado, en el Archivo General de la Guardia Civil, lo que refuerza el valor testimonial del documento. Este nos conecta con la voz de una víctima-testigo y, como se ha señalado más arriba, apenas se acompaña de observaciones del editor que vayan más allá de lo meramente descriptivo.

El autor del diario deja claras sus pretensiones: "Quiero dejar todo escrito para explicar a quien nos encuentre que él también es culpable, a no ser que sea otra víctima. Quien lea lo que escribo, por favor, que

\footnotetext{
${ }^{23}$ En cursiva en el original. Esto es válido para todas las citas de esta obra que aparecen aquí en cursiva.
} 
esparza nuestros restos por el monte" (MO: 41). Es decir, se dirige a los vivos, de quienes espera que dejen sus cadáveres esparcidos por el monte. Si no son víctimas como él, deben sentirse culpables del desolador desenlace que ha tenido la huida de la familia ${ }^{24}$. Aunque la guerra ya ha finalizado, la derrota es la causa última de la muerte de la pareja y su bebé: "Y de derrota ha muerto Elena y de derrota morirá mi hijo (...). Mi hijo (...) morirá enfermo de derrota" (MO: 46).

En todo momento queda constancia de que la escritura del diario no es un desahogo terapéutico, sino un ejercicio de ajuste de cuentas y el único camino posible para trascender a la propia condena ${ }^{25}$. A través de sus palabras, el republicano quiere hacer llegar la amargura de su fracaso a quienes están lejos de su encierro: "siento cierto placer morboso pensando en que alguien leerá lo que escribo cuando nos encuentren muertos al niño y a mí" (MO: 46). Frente a su indiferencia respecto a lo que ocurra con los cuerpos inertes de padre e hijo, se preocupa de preservar el diario, ya que este aparece -como señala el editor-narrador del relato en sus acotaciones-: "sobre un taburete bajo una pesada piedra que nadie hubiera podido dejar allí descuidadamente" (MO: 40). Así pues, son las palabras lo que ha de sobrevivir y cumplir su misión fuera del monte; frente a ellas, la parte corpórea de estos muertos parece ser intrascendente ${ }^{26}$.

Por otro lado, en lo que el editor sí adquiere un papel relevante es en la búsqueda de una identidad que rescate al autor del manuscrito del anonimato. A este respecto, el poeta de este hace lo mismo con su propio hijo. El bebé viene de la muerte y va hacia ella; en este sentido cierra un círculo perfecto en el que únicamente su efímera existencia

\footnotetext{
${ }^{24}$ La primera en fallecer es la madre del bebé, Elena, que no sobrevive al parto. Su cadáver convive con los demás en la cabaña hasta que finalmente el poeta se decide a enterrarlo.

${ }^{25}$ A este respecto, señala Cruz Suárez: "solo una actividad se erige como vehículo capacitado para ejercer una suerte de resistencia frente a la muerte: la escritura" (2013: 110). ${ }^{26} \mathrm{El}$ autor explica que su inspiración parte de un hecho real: "Lo del poeta escondido en las brañas también es cierto. Yo hablé con el pastor que encontró los esqueletos en 1940, en los altos de Somiedo. Me contó que en la cabaña había una bandera republicana, pero yo lo eliminé. He quitado todo lo que fueran grandes gestos, he intentado no hacer ninguna proclama" (Rendueles, 2004). A través del relato, Méndez dota de voz a cadáveres cuya memoria se ha desvanecido en el anonimato. Este quedará asimismo anulado, pues los dos cuerpos serán provistos de nombre, bien en la parte ficcional o en la metaficcional.
} 
vital distorsiona su no-ser. Solo recibe un nombre después de fallecer, el mismo que su abuelo. El cuerpecillo deja de tener un significado, pues este se transfiere al nombre que acaba de concedérsele: "El resto de la página (...) repite «Rafael», «Rafael», «Rafael» hasta sesenta y tres veces" (MO: 56). De nuevo queda claro que el refugio de los muertos está en las palabras, sean estas sus nombres o la voz de su memoria, solo ellas pueden conectarlos con la memoria de los vivos.

Los esfuerzos del editor en averiguar la identidad del poeta tienen que ver no solo con la curiosidad propia, sino también con la presunción -deducible del testimonio- de que este confiaba en que sus palabras iban a trascender. A este respecto señala Thomas W. Laqueur: "The dead we imagine do not want to be forgotten and are reluctant to go, and we -the living- are reluctant to let them go or forget them thereby we truly lose them" (2015: 62). Como se indicó más arriba, solo al final del relato se da a conocer la identidad del autor del manuscrito ${ }^{27}$. Esto cierra el proceso que el propio poeta ha iniciado tras poner nombre a su hijo: "La aparición de ese nombre, Eulalio Ceballos, es necesaria para, de esa manera, cerrar el ciclo de reestablecimiento [sic] de la identidad nominal de los cuerpos encontrados en el monte" (Cruz Suárez, 2013: 107). El nombre y los apellidos sacan a la víctima de la "fosa común" de la historia y otorgan al diario una entidad concreta, transferible eso sí al conjunto de los muertos que tuvieron un destino semejante.

\section{Bibliografía}

Assmann, Aleida. 2010. Re-framing Memory: Between Individual and Collective Forms of Constructing the Past. In Tilmans, Karin; Van Vree, Frank \& Winter, Jay (eds.) Performing the Past: Memory, History, and Identity in Modern Europe. Ámsterdam: Amsterdam University Press, 35-50. Assmann, Aleida. 2011. Wem gehört die Geschichte? Internationales Archiv für Sozialgeschichte der deutschen Literatur 36(1), 213-225.

Beattie, Andrew. 2006. The Victims of Totalitarism and the Centrality of Nazi Genocide: Continuity and Change in German Commmemorative

\footnotetext{
${ }^{27}$ Cuando el editor acude a la aldea cántabra de Caviedes en busca de información sobre el autor del manuscrito, también se encuentra con el nombre del maestro de este (don Servando, republicano ajusticiado) y los de sus padres: Rafael y Felisa (muertos al acabar la contienda).
} 
Politics. In Niven, Bill (ed.) Germans as Victims. Nueva York: Palgrave Macmillan, 147-163.

Bergmann, Michel. 2016. Weinhebers Koffer. Múnich: dtv.

Colmeiro, José. 2005. Memoria histórica e identidad cultural. De la postguerra a la postmodernidad. Barcelona: Anthropos.

Cruz Suárez, Juan Carlos. 2013. La muerte necesaria. El nombre como lugar posible de la memoria en la "Segunda derrota" de Los girasoles ciegos. En Cruz Suárez, Juan Carlos \& González Martín, Diana (eds.) La memoria novelada II. Ficcionalización, documentalismo y lugares de memoria en la narrativa memorialista española. Berna: Peter Lang, 103-119.

Frei, Norbert. 2009. 1945 und wir. Das Dritte Reich im Bewußtsein der Deutschen. Múnich: dtv.

González Márquez, Felipe. [1986] (Fecha de actualización de la página desconocida). Declaración institucional del gobierno con ocasión del cincuenta aniversario del comienzo de la guerra civil. https://www.elvalledeloscaidos.es/portal/?p=3470 [Acceso 18/03/2019].

Halbwachs, Maurice. 2004 [1950]. La memoria colectiva. Zaragoza: Prensas Universitarias de Zaragoza.

Herzberger, Julia. 2009. Erinnerungsarbeit der Holocaustliteratur der zweiten Generation. Göttingen: Optimus Mostafa Verlag.

Hirsch, Marianne. 2012. The Generation of Postmemory: Writing and Visual Culture after the Holocaust. Nueva York: Columbia University Press.

Hutcheon, Linda. 1988. A Poetics of Postmodernism. Nueva York/Londres: Routledge.

Huyssen, Andreas. 2003. Present Pasts. Urban Palimpsests and the Politics of Memory. Standford: Standford University Press.

Jünke, Claudia. 2015. ¿Hacia una memoria transcultural? Reflexiones acerca de la narrativa memorialista española actual. En Suárez, Juan Carlos; Hansen, Hans Lauge \& Sánchez Cuervo, Antolín (eds.) La memoria novelada III. Memoria transnacional y anhelos de justicia. Berna: Peter Lang, 151-166.

Junquera, Natalia. 2009 (1 de marzo). Franco inventó la memoria histórica. El País. https://elpais.com/diario/2009/03/01/domingo/ $1235883156 \quad 850215 . \mathrm{html}$

Laqueur, Thomas W. (2015): The Work of the Death: A Cultural History of Mortal Remains. Princeton: Princeton University.

Mate, Reyes. 1991. La razón de los vencidos. Barcelona: Anthropos.

Mate, Reyes. 2003. Memorias de Auschwitz. Actualidad moral y política. Madrid: Trotta. 
Mate, Reyes. 2015. Memoria y construcción política. En Cruz Suárez, Juan Carlos; Hansen, Hans Lauge \& Sánchez Cuervo, Antolín (eds.) La memoria novelada III. Memoria transnacional y anhelos de justicia. Berna: Peter Lang, 25-38.

Méndez, Alberto. 2004. Los girasoles ciegos. Barcelona: Anagrama (incluye el relato Segunda derrota: 1940 o Manuscrito encontrado en el olvido, 37-57).

Pérez Garzón, Juan Sisinio \& Manzano Moreno, Eduardo. 2010. Memoria histórica. Madrid: CSIC/Catarata.

Rendueles, César. 2004. Alberto Méndez. La vida en el cementerio. Ladinamo septiembre-octubre (12). http://www.ladinamo.org/ldnm/articulo. php? numero=12\&id=298 [Acceso 05/04/2019].

Rothberg, Michael. 2009. Multidirectional Memory: Remembering the Holocaust in the Age of Decolonization. Standford: Standford University Press.

Santamaría Colmenero, Sara. 2012. Historia, testigo y nación en Mala gente que camina de Benjamín Prado. En Hansen, Hans L. \& Cruz Suárez, Juan Carlos (eds.) La memoria novelada. Hibridación de géneros y metaficción en la novela española. Berna: Peter Lang, 55-67.

Silva Barrera, Emilio. 2009. El trabajo de la Asociación para la Recuperación de la Memoria Histórica. En Olmos, Ignacio \& Keilholz-Rühle, Nikky (eds.) La cultura de la memoria. La memoria histórica en España y Alemania. Madrid: Iberoamericana, 173-184.

Schmitz, Helmut. 2004. On Their Own Terms. The Legacy of National Socialism in Post-1990 German Fiction. Birmingham: The University of Birmingham Press.

Steinecke, Hartmut. 2005. Literatur als Gedächtnis der Shoah. Paderborn: Ferdinand Schöningh.

Weizsäcker, Richard von. 2019. Zum 40. Jahrestag der Beendigung des Krieges in Europa und der nationalsozialistischen Gewaltherrschaft. http://www.bundespraesident.de/SharedDocs/Reden/DE/Richard-vonWeizsaecker/Reden/1985/05/19850508_Rede.html [Acceso 15/03/ 2019]. 